\title{
Resources for Structural Optimization of Gas-hydrodynamic Measuring Transducers
}

\author{
Yevhen Pistun, Halyna Matiko *, Hanna Krykh \\ Lviv Polytechnic National University, 12 Stepan Bandera St., Lviv, 79013, Ukraine
}

Received: November 05, 2021. Revised: December 14, 2021. Accepted: December 20, 2021.

(c) 2021 The Authors. Published by Lviv Polytechnic National University.

\begin{abstract}
The paper presents the analysis of the resources of structural and parametric optimization of gas-hydrodynamic measuring transducers of physical and mechanical parameters of fluids. Resources such as the number of throttles and their arrangement in the diagram, type of throttle elements, measuring channels with a certain type of output signal, the supply mode of the measuring transducer can be integrated into the design process of the measuring transducer of a specific parameter. A mathematical apparatus based on set theory and combinatorial analysis is proposed for synthesizing the possible structures of throttle diagrams, graph theory - for forming a set of measuring channels. The authors have given examples demonstrating the possibilities of building different diagrams of measuring transducers using the resources for structural synthesis. The proposed resources are the means of structural and parametric optimization for synthesizing the gas-hydrodynamic measuring transducers with optimal characteristics.
\end{abstract}

Keywords: measuring transducer; physical and mechanical parameters; throttle element; structural synthesis; structure of diagram.

\section{Introduction}

Many technological processes use automated measurement and control systems of physical and mechanical parameters of fluids, on which technical, economic, and quality indicators of production significantly depend. Measuring transducers of such systems are based on various measurement methods [1]-[3]. Due to significant potential to solve measurement problems, the gas-hydrodynamic throttle method has become widely used nowadays. Throttles are the sensing elements of gas-hydrodynamic measuring transducers [3], [4]. Transducers with throttles of different types are used to measure dynamic and kinematic viscosity of Newtonian liquids and gases, rheological characteristics of non-Newtonian fluids, low and micro flow rates of gases, analysis of the composition of gas mixtures, etc. [3]-[10].

For example, the transducer [6] for continuous measurement of the dynamic viscosity of Newtonian fluids consists of a viscosensitive unit with a laminar fluid flow and a serial connected turbulent flowmeter. The diagram also uses a second flowmeter shunting at least the viscosensitive unit. The viscosensitive unit can have a structure made up of capillary elements in parallel to expand the measuring range. Viscosity is determined by the ratio of the signals of both flowmeters.

In [7] a comparative analysis of capillary primary measuring transducers of low and micro flow rates of gases, built on different schematic diagrams: based on one capillary, a package of parallel connected capillaries and an unbalanced capillary bridge consisting of four capillaries with laminar fluid flow. All diagrams use output pressure stabilization, and a differential pressure gauge measures the output signal.

\footnotetext{
* Corresponding author. Email address: halyna.f.matiko@lpnu.ua
}

This paper should be cited as: Y. Pistun, H. Matiko, H. Krykh. Resources for structural optimization of gashydrodynamic measuring transducers. Energy Engineering and Control System, 2021, Vol. 7, No. 2, pp. 136 - 143. https://doi.org/10.23939/jeecs2021.02.136 
The transducers in [3] are used to measure the plastic viscosity and shear stress of viscoplastic fluids, the consistency coefficient, and the flow index of pseudo-plastic fluids continuously. They are built on a bridge diagram that uses laminar throttles with different geometric dimensions in its arms. Such transducers operate in a constant flow rate mode, and the output signals are measured using differential pressure gauges.

Turbulent throttle elements (orifice plates, nozzles) are widely used in differential pressure flowmeters of medium and high flow rates of liquids and gases. The methodology proposed in [8] allows designing flowmeters with the optimal accuracy of flow measurement. In [9], a device is built on a turbulent throttle, through which the investigated gasoline is pumped at a constant flow rate. Density is calculated by the pressure drop on the throttle measured using a differential pressure gauge. The octane number of gasoline is calculated based on the determined density using an artificial neural network.

Kinematic viscosity and density transducers are known with a combination of laminar and turbulent throttles connected in a bridge measuring diagram. The operation principle of transducers is based on balancing the bridge diagrams by changing the total flow rate of the controlled fluid [10]. In [11], the transducer of the combined parameter depending on dynamic viscosity and density is also developed based on the bridge diagram with oppositely connected laminar and turbulent throttles. But in such a transducer, an unbalanced bridge diagram is used, which operates in the mode of constant pressure drop in the supply diagonal. The pressure drop in the measuring diagonal of the bridge is the output signal.

The given examples of transducers built on different diagrams with different numbers and types of throttles, with different output signals, prove the wide possibilities of the gas-hydrodynamic method for measuring various parameters. At the same time, we should note that depending on the supply mode, the transducers built on the same structures with the same throttles can measure different technological parameters and the same parameters with different metrological characteristics: measuring range, measurement error, sensitivity, dynamic characteristics, etc.

A brief literature review of the developed gas-hydrodynamic transducers has shown that the functionality and goodness of the measuring transducer are determined on the one hand by characteristics of the diagram, its supply mode, and on the other hand - by constructive characteristics of the throttle elements used in the diagram. Therefore, the synthesis problem of high-quality gas-hydrodynamic measuring transducers must be solved by structural and parametric optimization methods, which are widely used for building various technical objects [12]. It is necessary to select the resources of structural synthesis among the optimization variables to describe potential structural diagrams of gas-hydrodynamic measuring transducers.

The paper aims to analyze and determine the resources of structural synthesis of gas-hydrodynamic transducers to choose the structural diagram of the measuring transducer of a specific physical and mechanical parameter of fluid, based on which it will be possible to ensure its optimal characteristics.

\section{Definition and substantiation of resources for structural optimization of gas-hydrodynamic measuring transducers}

The authors have proposed the following resources of structural synthesis to solve the problems of structural optimization of gas-hydrodynamic measuring transducers:

1) the diagram order that is the number of throttles in the diagram, and the arrangement of the throttles in the diagram;

2) the type of throttle elements in the diagram, which are described by different flow rate characteristics, depending on their constructive parameters and the flow regime of fluids;

3) measuring channels of the diagram with a specific type of output signal of the gas-hydrodynamic measuring transducer;

4) supply mode of the measuring transducer, which determines the additional equipping the diagram with the necessary technical means (stabilizers of pressure, pressure drop, flow rate, temperature, manometers, differential pressure gauges, flowmeters, etc.).

Let us analyze in more detail the resources of structural optimization of gas-hydrodynamic measuring transducers. 


\subsection{Order and structure of a throttle diagram}

The first resource is the number of throttle elements (diagram order) and their arrangement in the diagram. It is used to form different variants of throttle diagrams for measuring a specific parameter. The authors proposed a mathematical apparatus based on set theory and combinatorial analysis to synthesize all possible variants of throttle diagrams based on a certain number of elements [13], [14]. The concept of a tuple describes the serial connection of throttle elements. A new concept rank is proposed to describe diagrams with parallel connected throttle elements. It is a set of elements whose sequence changing does not create another rank, unlike tuples [15].

Thus, measuring diagrams of the $S$-th order, formed by serial connected primary elements, are described by a set $D_{S}^{\text {ser }}$ of tuples. It is found by combining sets formed by the direct Cartesian product of primary sets describing lower order diagrams, the sum of which equals $S[15]$ :

$$
D_{S}^{s e r}=\bigcup_{i=1}^{S-1}\left(D_{S-i} \times D_{i}\right)
$$

where $D_{i}$ is a set that describes a diagram of the $i$-th order.

Measuring diagrams of the $S$-th order, formed by parallel connected primary elements, are described by a set $D_{S}^{p a r}$ of ranks. It is found by combining sets formed by the indirect product of all sets describing lower order diagrams (the sum of their orders equals $S$ ). Subtracting from the set $D_{S}^{\text {par }}$ the completely intersecting sets we obtain:

$$
D_{S}^{p a r}=\bigcup_{i=1}^{S-1}\left(D_{S-i} * D_{i}\right),
$$

where $b=$ entire $(S / 2)$ is the nearest integer value, no more than $\mathrm{S} / 2$, i.e. $b \leq S / 2$.

We can find a set $D_{S}$ that describes all possible diagrams of the $S$-th order built on serial and parallel connections of throttle elements, as the union of the sets $D_{S}^{\text {ser }}$ and $D_{S}^{\text {par }}$ :

$$
D_{S}=D_{S}^{s e r} \cup D_{S}^{p a r}
$$

For example, the sets $D_{2}, D_{3}$ and $D_{4}$ describing the diagrams of the second, third and fourth order, according to formulas (1), (2), and (3), will have the form

$$
\begin{aligned}
D_{2}= & \left(D_{1} \times D_{1}\right) \cup\left(D_{1} * D_{1}\right) ; \\
D_{3}= & \left(D_{1} \times D_{1} \times D_{1}\right) \cup\left(\left(D_{1} * D_{1}\right) \times D_{1}\right) \cup\left(D_{1} \times\left(D_{1} * D_{1}\right)\right) \cup\left(\left(D_{1} \times D_{1}\right) * D_{1}\right) \cup\left(D_{1} * D_{1} * D_{1}\right) ; \\
D_{4}= & \left(D_{1} \times D_{1} \times D_{1} \times D_{1}\right) \cup\left(\left(D_{1} * D_{1}\right) \times D_{1} \times D_{1}\right) \cup\left(D_{1} \times\left(D_{1} * D_{1}\right) \times D_{1}\right) \\
& \cup\left(\left(\left(D_{1} \times D_{1}\right) * D_{1}\right) \times D_{1}\right) \cup\left(\left(D_{1} * D_{1} * D_{1}\right) \times D_{1}\right) \cup\left(D_{1} \times D_{1} \times\left(D_{1} * D_{1}\right)\right) \\
& \cup\left(\left(D_{1} * D_{1}\right) \times\left(D_{1} * D_{1}\right)\right) \cup\left(D_{1} \times\left(\left(D_{1} \times D_{1}\right) * D_{1}\right)\right) \cup\left(D_{1} \times\left(D_{1} * D_{1} * D_{1}\right)\right) \\
& \cup\left(\left(D_{1} \times D_{1} \times D_{1}\right) * D_{1}\right) \cup\left(\left(\left(D_{1} * D_{1}\right) \times D_{1}\right) * D_{1}\right) \cup\left(\left(D_{1} \times\left(D_{1} * D_{1}\right)\right) * D_{1}\right) \\
& \cup\left(D_{1} * D_{1} * D_{1} * D_{1}\right) \cup\left(\left(D_{1} \times D_{1}\right) *\left(D_{1} \times D_{1}\right)\right) \cup\left(\left(D_{1} \times D_{1}\right) * D_{1} * D_{1}\right) .
\end{aligned}
$$

It follows from expressions (4), (5), and (6) that there are two variants of second order diagrams, five different variants of third order diagrams, and fifteen different variants of fourth order diagrams (each subset included in the sets $D_{2}, D_{3}$ and $D_{4}$ describes a specific diagram structure).

Substituting a given set of primary elements $D_{1}$ into the equations (4), (5), or (6) and performing the corresponding operations of direct and indirect products of subsets, we find structures for all possible diagrams of the 
second, the third, or the fourth order, respectively. For example, for the simplest case, when $D_{1}=d$ (we use a throttle $d$ as a primary element) we obtain the following diagram structures:

$$
\begin{gathered}
D_{2}=\{<d, d>,[d, d]\} ; \\
D_{3}=\{<d, d, d>,<[d, d], d>,<d,[d, d]>,[<d, d>, d],[d, d, d]\} ; \\
D_{4}=\{\langle d, d, d, d>,<[d, d], d, d>,<d,[d, d], d>,<[<d, d>, d], d>, \\
<[d, d, d], d>,<d, d,[d, d]>,<[d, d],[d, d]>,<d,[<d, d>, d]>, \\
<d,[d, d, d]>,[<d, d, d>d],[<[d, d], d>, d],[<d,[d, d]>, d]>, \\
[d, d, d, d],[<d, d>,<d, d>],[<d, d>, d, d]\} .
\end{gathered}
$$

For example, Fig. 1 shows the measuring diagrams of the third order according to the expression (8).
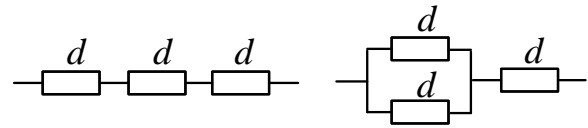

$<d, d, d>$

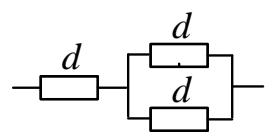

$<d,[d, d]>$

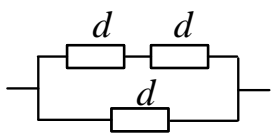

$[<d, d>, d]$

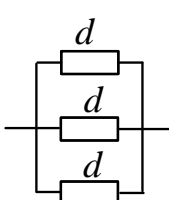

$[d, d, d]$

Fig.1. Diagrams of the third order.

Similar to the expressions (7)-(9), one can describe sets of diagrams of higher orders using a set of primary elements and obtain the descriptions of structures of all possible diagrams. Thus, the developed mathematical apparatus allows forming the whole set of throttle diagrams, based on which it is possible to synthesize gashydrodynamic devices and transducers with the necessary characteristics.

\subsection{Type of throttle elements}

The type of throttle elements in the diagram is the second resource of structural optimization. The flow rate characteristics of throttles determine their suitability for solving the problem of measuring a specific parameter. Throttle elements are laminar and turbulent, depending on their constructive characteristics and the flow regime of fluids. The fluid flows without mixing in laminar-type throttles. The pressure losses in such throttles are caused by friction between the layers parallel to the direction of fluid flow. In turbulent throttles, the fluid flow is characterized by the layers mixing, speed, and pressure pulsation. Local resistances cause pressure losses at the inlet and the outlet of the throttle [5].

The flow rate characteristic of the throttle element shows the relationship between the flow rate of the fluid flowing through the element and the pressure upstream and downstream of the element, its constructive characteristics, and the fluid parameters. In general, the flow rate characteristic of the throttle can be represented as [16]:

$$
Q=f\left(P_{\text {in }}, P_{\text {out }}, B_{c}, B_{p}, B_{e}\right),
$$

where $Q$ is the mass flow rate of the fluid through the throttle; $P_{\text {in }}$ and $P_{\text {out }}$ are the absolute pressures of the fluid at the inlet and the outlet of the throttle, respectively; $B_{c}, B_{p}$ and $B_{e}$ are the constructive, parametric and empirical complexes, respectively, which depend on the throttle design, the parameters of the fluid, and empirical coefficients that take into account the reality of the fluid and thermodynamic processes in the throttle element. Flow rate characteristics of different types of throttles are discussed in detail in [5].

\subsection{Measuring channels of a transducer}

Measuring channels are the third component of structural optimization of gas-hydrodynamic measuring transducers. They are created in the throttle diagram of the transducer to realize the measuring process. The authors developed a method for mathematical description of throttle diagrams with measuring channels based on graph theory 
[4]. It allows investigating the functionality of diagrams with different measuring channels to synthesize the schematic diagram of the measuring transducer of specific fluid parameters. It is known that the connections of throttles, which are called diagram nodes, are used to build measuring channels. Such nodes of the diagram, numbered in a certain way, are the graph vertices, and the measuring channels are the graph edges. If the output signal is a pressure drop between different diagram nodes, the measuring channel is described by an edge without a direction connecting two graph vertices. In this case, we obtain a simple undirected graph.

In [17], the authors used the concept of an empty, complete and partial graph to describe the throttle diagrams with measuring channels. An empty graph describes a throttle diagram without measuring channels. A complete graph covers all possible measuring channels that can be created in a given diagram. The authors proposed to use a formula for determining the number $m$ of all measuring channels that can be formed in a given throttle diagram with $n$ nodes:

$$
m=\frac{n(n-1)}{2}
$$

The number $n$ of nodes in the throttle diagram determined by the throttles arrangement can be calculated with the formulas given in [4].

Usually, all measuring channels are not simultaneously used in the throttle diagram to measure fluid physical and mechanical parameters. The authors recommended using partial graphs to describe such variants of measuring transducers with one, two, and more measuring channels. The set of all partial graphs of the complete graph covers all possible variants for building measuring transducers on a throttle diagram of a certain type, which will differ in combinations of measuring channels.

Taking into account that the diagram without measuring channels is described by an empty graph, based on the formula for calculating the number of partial subgraphs of a graph of size $m$ [17], the authors obtained the equation for determining the number $n_{M T}$ of all variants for building measuring transducers:

$$
n_{M T}=2^{m}-1 .
$$

For example, Fig. 2 shows a fourth order throttle diagram with four nodes $(n=4)$ and its equivalent graph, which describes all possible measuring channels in this diagram $(m=6)$. The number of all variants of measuring transducers on such a throttle diagram with different measuring channels $n_{M T}=63$.
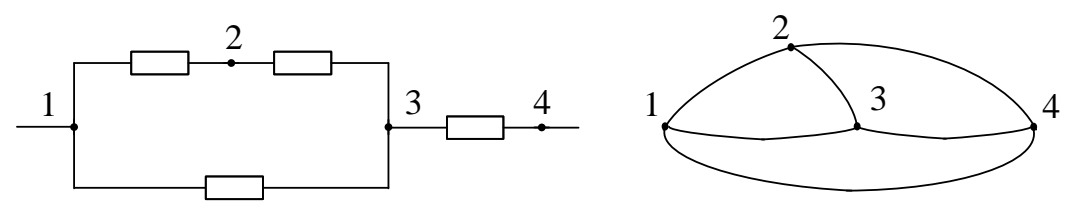

Fig.2. Throttle diagram of fourth order $\langle[\langle d, d\rangle, d], d\rangle$ and its equivalent graph.

Thus, the graphs make it possible to describe the set of nodes of any throttle diagram and the set of measuring channels. If we take into account the transform functions of each measuring channel corresponding to the graph edges, we obtain a loaded graph, based on which it is possible to build mathematical models of measuring transducers.

We should also note that in addition to the pressure drop, there are some other output signals of throttle diagrams, such as the fluid flow rate through the throttle or a set of throttles, pressures at the throttles' connections. They are chosen according to the task of measuring a specific parameter.

\subsection{Supply mode of a measuring transducer}

The supply mode of the measuring transducer is the fourth resource of structural optimization. The basic principle of building transducers ensures stabilization of some parameters in the mathematical model of the transducer, particularly non-informative ones, except for input and output parameters. Therefore, gas-hydrodynamic transducers usually operate in a constant flow mode, a constant pressure, or a constant pressure drop. To create such modes in the throttle diagram, one should supply additional elements that ensure measurement or stabilization of the 
required parameters - measuring transducers of pressure, pressure drop, flow rate, temperature, or control systems, or stabilizers of these values, etc.

For example, let us consider some of the possible variants of measuring transducers based on one throttle element. Thus, equation (10) includes six parameters: $P_{i n}, P_{\text {out }}, B_{c}, B_{p}, B_{e}, Q$. Each of these parameters can be the input signal of the measuring transducer, as well as each parameter that influences the complexes $B_{c}$, $B_{p}$ and $B_{e}$, i.e. $\left\{P_{\text {in }}, P_{\text {out }}, Q, X\right\} \in X_{i n}$, where $X$ is any parameter included in the complexes $B_{c}, B_{p}$ and $B_{e}$ or influences these complexes. The output signal can be either flow rate, inlet pressure, or outlet pressure of the throttle $\left\{P_{\text {in }}, P_{\text {out }}, Q\right\} \in X_{\text {out }}$. All other parameters, except input and output, must be constant or stabilized, and their values must be known.

Fig.3 shows some examples of measuring transducers of the parameter $X$ (density, viscosity, isentropic exponent of the fluid, etc.) based on one throttle element for compressible and non-compressible fluids. We can see the transform function in the form $X_{\text {in }} \Rightarrow X_{\text {out }}$ under each transducer diagram, where $X_{\text {in }}$ is the transducer input signal, $X_{\text {out }}$ is the transducer output signal.

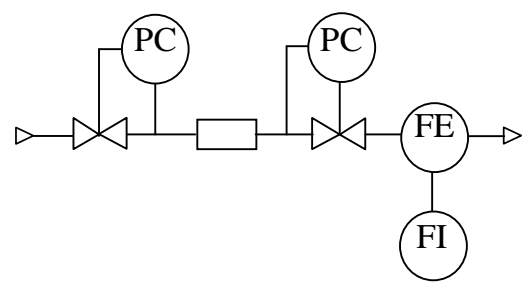

a) $X \Rightarrow Q$

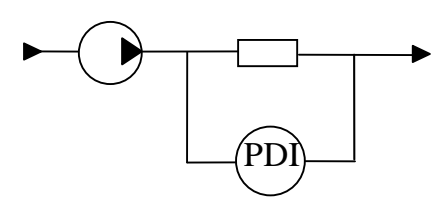

b) $X \Rightarrow \Delta P$

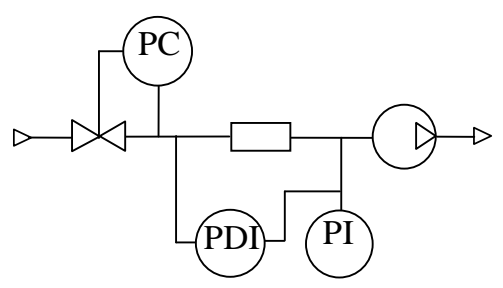

c) $X \Rightarrow P_{\text {out }}(\Delta P)$

Fig.3. Examples of measuring transducers of the parameter $X$ based on one throttle element.

Fig.3, $a$ shows a diagram of the measuring transducer of the parameter $X$ of the compressible fluid, which ensures stabilization of the inlet $P_{\text {in }}$ and outlet $P_{\text {out }}$ pressure of the throttle to ensure the necessary operating conditions. The fluid flow rate $Q$ measured by a flowmeter is the output signal of the transducer. Fig.3, $b$ shows a diagram of the measuring transducer of the parameter $X$ of the incompressible fluid with a constant flow rate. The pressure drop across the throttle measured by a differential pressure gauge is the output signal of such a diagram. Fig.3, $c$ shows another diagram of the measuring transducer of the parameter $X$ of the compressible fluid, which ensures a constant fluid flow rate $Q$ and the stabilization of the inlet pressure $P_{\text {in }}$ and outlet pressure $P_{\text {out }}$ of the throttle element. The outlet pressure $P_{\text {out }}$ of the throttle element or the pressure drop $\Delta P$ across the throttle is the output signal of such a diagram. It is measured by a manometer or a differential pressure gauge, respectively.

Let us also consider examples of measuring transducers based on throttle diagrams of the second order. To measure any of the parameters $X$ that influence the complexes $B_{c}, B_{p}$ and $B_{e}$, the transducer can be built according to various diagrams, some of which are shown in Fig.4.

The diagram in Fig.4, $a$ provides stabilization of the inlet pressure $P_{i n}$ of the compressible fluid of the first throttle and the outlet pressure $P_{\text {out }}$ of the second throttle. The output signal of this diagram is the pressure $P_{A}$ between two throttles measured in node $A$ of the diagram using a manometer. The transducer is easily realized according to such diagram. It does not require measuring the fluid flow rate compared to the similar diagram based on one throttle element (Fig.3,a). In addition, measuring the inter-throttle pressure $P_{A}$ may be replaced by measuring the pressure drop across one of the throttles. This diagram can also be used in the other more complex throttle measuring diagrams - bridge and differential [11], [16].

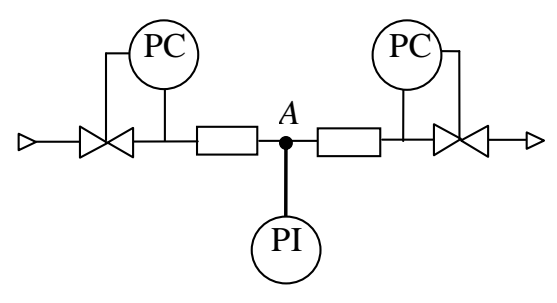

a) $X \Rightarrow P_{A}$

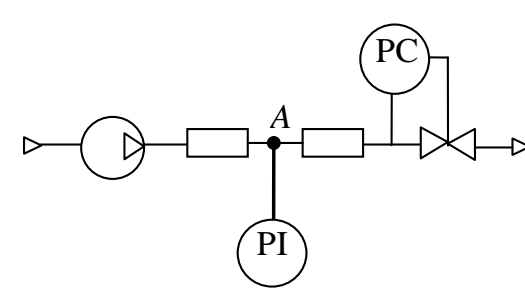

b) $X \Rightarrow P_{A}$

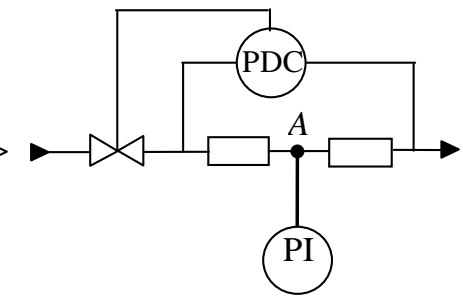

c) $X \Rightarrow P_{A}$

Fig.4. Examples of diagrams of measuring transducers of parameter $X$ based on two throttle elements. 
The second transducer diagram (Fig.4,b) is also used to measure the parameter $X$ of a compressible fluid. The diagram provides a constant flow rate $Q$ of the fluid and stabilization of one of the supply pressures, particularly the pressure $P_{\text {out }}$. The pressure $P_{A}$ in diagram node $A$ between two throttles is the output signal of this diagram, which is measured by a manometer. Fig.4, $c$ shows a diagram of the measuring transducer of the parameter $X$ of an incompressible fluid, which ensures the pressure drop $\Delta P$ stabilization on two serial connected throttles. The interthrottle pressure $P_{A}$ is the output signal of this diagram too. It is measured in diagram node $A$ between two throttles by a manometer. We can see from the diagrams shown in Fig.3, Fig.4, depending on the supply mode, measuring transducers have different types of output signals: flow rate, pressure drop across the throttle, pressure at the connection of throttles.

Each of the above resources of structural synthesis can take different values or modifications, and all of them together can be in various combinations, forming a set of possible schematic diagrams of measuring transducers. To measure a specific physical and mechanical parameter of the fluid, one chooses from this set such diagrams for the gas-hydrodynamic transducer, which primarily provides the necessary functionality. Then, analyzing the subset of the sorted diagrams, one chooses the diagram of the measuring transducer with the specified technical characteristics using the methods of parametric optimization.

\section{Conclusion}

As a result of the analysis of diagrams and characteristics of gas-hydrodynamic throttle transducers, the resources of diagrams structural synthesis for measuring the physical and mechanical parameters of fluids are defined. They are the number of throttles and their arrangement in the diagram; type of throttle elements; measuring channels with certain types of the output signal, supply mode of the measuring transducer. The authors developed a mathematical apparatus based on set theory and graph theory to form the proposed resources of structural synthesis. The practical application of the obtained results is the possibility to synthesize various structural diagrams of gashydrodynamic throttle transducers. The obtained results will be further applied to develop the technique for structural and parametric optimization for automated design of measuring transducers of specific physical and mechanical parameters of fluids.

\section{References}

[1] Van der Wouden, E., Groenesteijn J., Wiegerink R., Lötters J. (2015) Multi Parameter Flow Meter for On-Line Measurement of Gas Mixture Composition. Micromachines, 6(4), 452-461. doi: 10.3390/mi6040452

[2] Niedermayer, A. O., Voglhuber-Brunnmaier T., Feichtinger F., Heinisch M., Jakoby B. (2016) Monitoring Physical Fluid Properties Using a Piezoelectric Tuning Fork Resonant Sensor. BHM Berg- und Hüttenmännische Monatshefte, 161(11), 510-514. doi: 10.1007/s00501-0160540-0

[3] Pistun, Ye., Matiko, H., Krykh, H., Matiko, F. (2017) Synthesizing the Schemes of Multifunctional Measuring Transducers of the Fluid Parameters. Eastern-European Journal of Enterprise Technologies, 6, 5(90), 13-22. https://doi.org/10.15587/1729-4061.2017.114110

[4] Pistun, Ye., Matiko, H., Krykh, H., Matiko, F. (2018) Structural Modeling of Throttle Diagrams for Measuring Fluid Parameters. Metrology and Measurement Systems. 25(4), 659-673. doi: 10.24425/mms.2018.124884

[5] Pistun Y., Matiko H., Krykh H. (2019) Mathematical Models of Throttle Elements of Gas-hydrodynamic Measuring Transducers. Energy Engineering and Control Systems, 5(2), 94-107. https://doi.org/10.23939/jeecs2019.02.094

[6] Nitecki J.-P., Patrick S., U.S. Patent 6,073,483. (2000) Device for Measuring the Viscosity of Fluid

[7] Teplukh Z., Dilay I., Stasiuk I., Tykhan M., Kubara I. (2018) Design of Linear Capillary Measuring Transducers for Low Gas Flow Rates. Eastern-European Journal of Enterprise Technologies, 6/5 (96), 25-32. doi:10.15587/1729-4061.2018.150526

[8] Pistun, Y., Lesovoy, L., Matiko, F., Fedoryshyn, R. (2014) Computer Aided Design of Differential Pressure Flow Meters. World Journal of Engineering and Technology. 2, 68-77. doi:10.4236/wjet.2014.22009

[9] Drevetskiy V., Klepach M. (2012) The Method for Determining the Octane Number of Automotive Gasoline of Different Types. Patent UA No. 75959. Bul. No.24 (in Ukrainian)

[10] Drevetskiy V., Klepach M. (2013) The Intelligent System for Automotive Fuels Quality Definition, "Informatics, Control, Measurement in Economy and Environment Protection”, 3 (3), 11-13. doi:10.35784/iapgos. 1455

[11] Pistun Ye. P., Matiko H. F., Krykh H. B., Matiko F. D. (2021) Modeling Throttle Bridge Measuring Transducers of Physical-Mechanical Parameters of Newtonian Fluids. Mathematical Modeling and Computing, 8 (3), 515-525. doi: 10.23939/mmc2021.03.515

[12] Zosimovych N. (2016) Structural and Parametric Optimization for Flight Vehicle Structures. Conference: “Areas of Scientific Thought 2016/2017', XII International Scientific and Practical Conference, December, 30, 2016 - January, 7, 2017, Technical Science. At: Sheffield, UK: Vol. 8, 59-68.

[13] Winskel G., (2010) Set Theory for Computer Science. 
[14] Keller M., Trotter W., (2015) Applied Combinatorics.

[15] Pistun Ye., Matiko H., Krykh H., (2016) Modeling the Measuring Transducers Schemes Using Set Theory, Metrology and Instruments, 3, 53-61. (in Ukrainian)

[16] Pistun, Ye., Leskiv, H. (2002) Gas-hydrodynamic Measuring Transducers Built on Complex Throttle Elements. Bulletin of Lviv Polytechnic National University: Heat Power Engineering. Environmental Engineering. Automation, 460, 81-88. (in Ukrainian)

[17] Diestel, R. (2016) Graph Theory. Springer-Verlag, Heidelberg.

\title{
Ресурси структурної оптимізації газогідродинамічних вимірювальних перетворювачів
}

\author{
Євген Пістун, Галина Матіко, Ганна Крих \\ Національний університет «Львівська політехніка», вул. Степана Бандери, 12, Львів, 79013, Україна
}

\begin{abstract}
Анотація
В статті проаналізовано та обгрунтовано ресурси структурного синтезу схем газогідродинамічних дросельних перетворювачів для вимірювання фізико-механічних параметрів плинних середовищ. Такі ресурси, як кількість дроселів в схемі та їх компонування; тип дросельних елементів; вимірювальні канали 3 певним типом вихідного сигналу, режим живлення вимірювального перетворювача можуть бути інтегровані в процес проектування вимірювального перетворювача конкретного параметра. Для формування можливих структур дросельних схем, зокрема, запропоновано математичний апарат на основі теорії множин та комбінаторного аналізу, для формування множини вимірювальних каналів - теорія графів. Наведені приклади, які демонструють можливості побудови різних схем вимірювальних перетворювачів за допомогою розглянутих ресурсів структурного синтезу. Запропоновані ресурси є засобами структурно-параметричної оптимізації для створення газогідродинамічних вимірювальних перетворювачів із оптимальними характеристиками.
\end{abstract}

Ключові слова: вимірювальний перетворювач; фізико-механічні параметри; дросельний елемент; структурний синтез; структура схеми. 